\title{
Julio Cortázar, viajero en el trópico: promesa vanguardista y cultura transnacional frente al proyecto político sandinista
}

\begin{abstract}
Julio Cortázar, Traveller in the Tropics: Vanguardist Promise and Transnational Culture before the Sandinista Political Project. Julio Cortázar, viajante no trópico: promessa vanguardista e cultura transnacional na frente do projeto político Sandinista.
\end{abstract}

\section{Leonel Delgado Aburto}

\author{
UNIVERSIDAD DE CHILE, CHILE
}

Profesor de la Facultad de Letras de la Universidad de Chile. PhD

University of Pittsburgh. Autor de varios artículos en revistas especializadas y de los libros Márgenes recorridos: apuntes sobre procesos culturales y literatura nicaragüense del siglo XX (Instituto de Historia de Nicaragua y Centroamérica, 2002), Excéntricos y periféricos: escritura autobiográfica y modernidad en Centroamérica (IILI, 2012).Correo electrónico: ldelga_ni@yahoo.com

\footnotetext{
Artículo de Reflexión

El artículo pertenece al proyecto de desarrollo de una línea de investigación sobre Centroamérica y el Caribe en el Centro de Estudios Culturales Latinoamericanos de la Universidad de Chile. Una versión muy preliminar del texto fue leída como ponencia en el II Congreso Centroamericano de Estudios Culturales, San José, Costa Rica, julio de 2009. Documento accesible en línea desde la siguiente dirección: http://revistas.javeriana.edu.co 


\section{Resumen}

Este artículo aborda la vinculación de Julio Cortázar con Nicaragua y la revolución sandinista, argumentando que esta relación tiene como base la actitud vanguardista de Cortázar. Así, su compromiso político se relaciona con una radicalidad estética presente en toda su obra. Además, el artículo propone que en el compromiso de Cortázar con la revolución sandinista se interrelacionan las figuras del viajero, el turista político y el intelectual comprometido. En el viaje de Cortázar al trópico, este proyecto vanguardista sufre transformaciones relacionadas con el pensamiento sobre la soberanía territorial de Nicaragua, para lo cual se analizan partes de su libro Nicaragua tan violentamente dulce.

\section{Palabras clave: Cortázar; Nicaragua; revolución sandinista; vanguardia; transnacionalismo}

\section{Abstract}

This article analyzes the relationship of Julio Cortázar with Nicaragua and the Sandinista revolution. This relationship is based on Cortázar's modernist/ vanguardist position. Therefore, his political engagement is linked to an aesthetic radicalism that can be found in his entire oeuvre. Furthermore, the paper argues that in Cortázar's engagement with the Sandinista revolution the figures of traveler, political tourist and engaged intellectual are intertwined. Along the travel of Cortázar through the tropics, his modernist/ vanguardist project undergoes a transformation related to the reflection on Nicaraguan territorial sovereignty. To show this change some parts of his book Nicaragua tan violentamente dulce are analyzed.

Keywords: Cortázar; Nicaragua; Sandinista revolution; vanguard; vanguarda; transnacionalismo transnationalism

\section{Resumo}

Este artigo aborda a vinculação de Julio Cortázar com a Nicaragua e a revolução Sandinista, argumentando que esta relação tem como base a atitude vanguardista de Cortázar.

Assim, seu compromisso político relaciona-se com una radicalidade estetica presente na sua obra inteira. Além, o artigo propõe que no compromisso de Cortázar com a revolução Sandinista inter relacionamse as figuras do viajante, o turista político e o intelectual comprometido. Na viajem de Cortazár ao trópico este projeto vanguardista sofre transformações relacionadas com o pensamento sobre a soberania territorial da Nicaragua para o qual analisam-se partes de seu livro Nicaragua tão violentamente doce.

Palavras-chave: Cortázar; Nicaragua; revolução Sandinista; vanguarda, transnacionalismo

RECIBIDO: 5 DE MARZO DE 2014. APROBADO: 7 DE ABRIL DE 2014. DISPONIBLE EN LÍNEA: 15 DE ENERO DE 2015

\section{Cómo citar este artículo:}

Delgado Aburto, Leonel. "Julio Cortázar, viajero en el trópico: promesa vanguardista y cultura transnacional frente al proyecto político sandinista". Cuadernos de Literatura 19.37 (2015): 83-101. doi:10.11144/Javeriana.CL19-37.jcvt 
EN 1976 JULio Cortázar ingresó de manera clandestina a Nicaragua, en compañía de Sergio Ramírez y Ernesto Cardenal, para visitar la comunidad evangélica que Cardenal dirigía en las islas de Solentiname, en el lago de Nicaragua. Esa visita produjo la que es la principal inscripción textual de la relación entre Cortázar, la cultura nicaragüense y el sandinismo. ${ }^{1}$ El texto "Apocalipsis de Solentiname" (incluido en el volumen de cuentos Alguien que anda por ahí, de 1978, y recogido también en Nicaragua tan violentamente dulce, 1984) recrea esa visita y presenta una visión del terror político de las dictaduras latinoamericanas que se superpone a las pinturas naíf o primitivistas producidas por los campesinos de las islas. En la narración, Cortázar, narrador y protagonista, ha fotografiado las pinturas en Nicaragua para proyectarlas privadamente en una pantalla de su apartamento de París. La presentación se ve interrumpida, sin embargo, por imágenes de persecuciones, torturas, asesinatos y represión que podrían ser las de casi cualquier país latinoamericano de la época (incluyendo por supuesto la Nicaragua de la dictadura somocista), y refiriéndose con énfasis al asesinato del poeta salvadoreño Roque Dalton. El Apocalipsis al que alude el título implica la destrucción del Paraíso previsto en las pinturas de los campesinos. Hay, obviamente, un énfasis visual u óptico en la narración y una referencia a diversos medios de reproducción y estéticas diferenciadas: la pintura naíf, la fotografía y la proyección. Asimismo, el texto responde a ciertas marcas de la literatura de viajes (por ejemplo el contraste entre el aquí y el allá, la seguridad de París versus el peligro de Solentiname) que lleva a pensar en una constante constructiva de la cultura latinoamericana propiciada por la narrativa de viajes. Cortázar, convertido en viajero en el trópico en virtud de encarnar el rol de intelectual revolucionario, ${ }^{2}$ parece revivir, si bien en otra clave, una tradición establecida en los relatos coloniales y neocoloniales. El evento político constituido por la revolución sandinista en Nicaragua, a partir de los procesos de insurrección (1977-1979) y de gobierno revolucionario (1979-1989) atrae a intelectuales y escritores entre otros tantos sujetos que colaboran como combatientes o en actividades de solidaridad, encarnando lo que más contemporáneamente se ha denominado "turismo político". Para Moynagh (2008) esta caracterización, lejos de ser peyorativa, mantiene estratégicamente tanto la distancia cultural del viajero que se vincula con una lucha política - que en principio no es suya- como los efectos de tal compromiso.

1 Principal, al menos, por la recepción crítica. Quisiera destacar las lecturas de Alberto Moreiras, que retomaré más adelante, afiliada a una teorización subalternista, y la de Paz Soldán, que relaciona el texto de Cortázar con la obra de Roberto Bolaño.

2 Para el tránsito de "escritor burgués a intelectual revolucionario" de Cortázar, a través de una atenta lectura de su correspondencia de los años sesenta, ver Gilman. 
Así, la designación implicaría tanto la relación desigual de la modernidad (al cruzar el intelectual comprometido bordes y fronteras internacionales) como la imaginación política del compromiso y sus efectos afiliativos (Moynagh 9). ${ }^{3}$ En ese sentido, Julio Cortázar encarna, sin duda, un caso notable de turista político, quien desde la época insurreccional (1977) hasta su muerte (1983) visita varias veces Nicaragua, desarrolla una febril actividad de solidaridad, escribe de forma más o menos abundante sobre la revolución sandinista, y produce incluso una reinscripción de su figura en textos de escritores nicaragüenses. ${ }^{4}$ CCómo caracterizar al viajero o turista político Cortázar y cómo dar cuenta de su disonancia con relación a la tradición de los textos de viaje que no implican un compromiso político, o, en el otro extremo, que están signados por un modelo (neo)colonial?

La hipótesis de partida de este artículo es que Cortázar inscribe en el modelo del viaje una propuesta heterológica vanguardista, esto es, una búsqueda o autorización de la lógica del otro. Esta reinscripción lo lleva a replantear los principios de esa tarea en consonancia con la constitución de la soberanía territorial revolucionaria en Nicaragua a partir de 1979, en un momento que tal soberanía es un proyecto incipiente y amenazado por la guerra contrarrevolucionaria (sobre todo a partir de 1982). En otras palabras: el proyecto vanguardista de Cortázar asume una lógica soberana para el territorio de la solidaridad - en este caso, $\mathrm{Ni}$ caragua-. Consideraré, además, que una plataforma de acción fundamental de Cortázar es la cultura internacional o transnacional, activada fundamentalmente por el que fuera llamado "boom" de la literatura latinoamericana, lo que determina aspectos importantes en su posición como viajero. Entonces, en una primera parte del artículo presentaré consideraciones en torno a la actitud vanguardista de Cortázar en la que se vería inscrito su compromiso político (actitud que en el presente aparece deteriorada dados los cambios políticos traídos por la dominante neoliberal). En segundo lugar plantearé cómo la figura del viajero Cortázar, que combina al intelectual comprometido, el escritor célebre y el turista político, aparece ligada al desarrollo de una cultura transnacional latinoamericana que se vincula con la revolución sandinista. Aun así, ubicado en el terreno de la circulación - que es también el del mercado-quisiera plantear que es posible advertir

3 Moynagh analiza un libro paradigmático de las actividades de solidaridad intelectual con la revolución sandinista: la memoria de Salman Rushdie, The faguar Smile (177-212). Centroamérica convocó en los años 1980s una serie de discursos sobre su exoticidad y distancia, como se puede ver en el análisis de David Spurr sobre el libro de Joan Didion, Salvador (166-168). Ver también el ensayo de Neil Larsen (39-51) sobre Centroamérica como territorio "sin historia" en la representación cinematográfica hollywoodense de esos años. 
en Cortázar una imaginación política que busca trascender esa lógica separadora. Así, en tercer lugar, tomando como base el texto "Retorno a Solentiname", incluido en Nicaragua tan violentamente dulce, intentaré una lectura alegórica en la que el viajero quiere revelar lo reprimido (bárbaro y amenazante, tras su evidente belleza) del paisaje tropical, metonimia del proyecto político sandinista del momento, en cuya perspectiva se conjugan la visión del viajero, el turista político y el escritor vanguardista como puntos de soporte de una figuración alegórica.

\section{La heterología en ruinas: el proyecto vanguardista de Cortázar}

En las lecturas de la obra de Julio Cortázar se ha exaltado su compromiso éticoestético con la izquierda pero también se ha condenado la supuesta simpleza y superficialidad de tal compromiso. El mismo Cortázar parece usar con frecuencia la máscara retórica del que no sabe nada de política y opina desde un ámbito prístino, inocente o, incluso, "idiota" (Nicaragua tan violentamente dulce 8). En el primer caso, es decir, la lectura comprobatoria del proyecto político de Cortázar, se ha notado la fuente heterológica y vanguardista que orienta su giro político a partir de los sesenta, enfatizando el carácter de resistencia de su literatura, para lo cual el texto "Apocalipsis de Solentiname", que como ya dije es el punto de contacto inicial de Cortázar con la revolución sandinista, ha constituido un eje significativo. ${ }^{5}$ Para señalar un ejemplo clave de lectura que acata al Cortázar comprometido se puede referir a la lectura deconstructiva-subalternista que hace Alberto Moreiras de "Apocalipsis", que propende a un exterior del concepto limitadamente literario de autor y obra, encarnado en la política subalterna. Según la explicación parcialmente psicoanalítica que hace Moreiras, el texto de Cortázar implica dos tipos de escritura, una fundacional (que sería la escritura motivada por la visión primitivista del mundo, vista en las pinturas de los campesinos de Solentiname) y otra abyecta o sacrificial que presenta el narrador a través de las imágenes apocalípticas. Esta última domina el texto como excrecencia producida a partir de la visualidad, revelando un inconsciente óptico que posibilita articular la emancipación. Moreiras plantea que: "La ontología que subyace a cualquier proyecto emancipatorio está siempre sujeta a [la] crítica heterológica" (365),

5 Una lectura general fundamental del tema es la de Alazraki (1987). Para la lectura desde el tópico de la resistencia, ver Harlow (1987). Sobre la ambigüedad interpretativa de "Apocalipsis", lectura histórica y estética, ver Titler (1987). Importante para una interpretación del sentido retórico del compromiso político de Cortázar, a partir del cuento "Reunión", ver González (1987). Recientemente Jaume Peris Blanes muestra como el cuento "El perseguidor" representa, asimismo, una inflexión estético-política. 
proceso que entra en acción con la escritura destructiva, "de traducción, [y] de resta" (364). Queda explícito así un movimiento de "ruptura de la mímesis" y de "desastre de la ontología" que posibilita un asiento a la "política emancipatoria" (357).

Como remarcaré más adelante, creo que esta intervención destructiva se articula de forma alegórica y refiere a la lucha del texto cortazariano por salir de una lógica trascendente autorreferida - la que incluye el mito de la obra y el autor- a través de un potencial desborde de la configuración que autoriza esa trascendencia. Obviamente, esta contradicción tiene un alcance mucho más vasto dentro de la obra y la vida política de Cortázar. Mi argumento sería que el llamado compromiso político de Cortázar es el elemento clave de esa lucha en contra de la literatura como orbe autorreferencial, que no es un asunto coyuntural (o compromiso eventual) sino que conmueve el fundamento de cierto entendimiento letrado del poder y la vida. En segundo lugar tendría que decirse que es precisamente este rompimiento ante el cual se duda cuando se critica el compromiso de Cortázar: la supuesta frivolidad, superficialidad o cursilería de su opción política. Así, en contraste con la exaltación del Cortázar comprometido, Ángel Rama mostró tempranamente, aunque en privado, su fuerte disgusto ante lo que juzgaba la ingenuidad política de Cortázar. El posicionamiento intuitivo, esteticista o vital que Cortázar repite de manera estrategia en toda una etapa de su desarrollo como autor comprometido, ${ }^{6}$ es considerado por Rama de la siguiente forma:

Desagrado, cólera y más tarde una larga, larga depresión, cuando oí a Cortázar en el acto de presentación de la revista Sin Censura que él patrocina en París. Me consta su falta de información política y no digamos económica o social, y su escaso discernimiento para la problemática internacional. Como él confiesa, hasta mediados de los sesenta era un literato puro que además nada sabía de América Latina. Lo desgraciado es que no ha hecho reales esfuerzos para informarse mejor, estudiar los problemas y verlos con una perspectiva objetiva. Pero a pesar de que sigue siendo un "literato puro" opina sobre política con tal simpleza, ignorancia de los asuntos y elementalidad del razonamiento, que produce o descorazonamiento o cólera. A mí las dos cosas y concluyo

6 Su relación con Casa de las Américas, con situaciones tan tirantes como el caso Padilla, con el sandinismo y con Argentina (visible en el póstumo Años de alambradas culturales) desmiente el nivel meramente "intuitivo" de tal compromiso, aunque sea la alusión a esa "intuición" una verdad central pero también una máscara reiterada por Cortázar (al respecto véase "Apuntes al margen de una relectura de 1984" en Nicaragua tan violentamente dulce, 8-17, en que se retrata irónicamente como "idiota"). 
abominando de los escritores metidos a políticos: concluyen haciendo mal las dos cosas (Diario 153).

En resumen, al confrontarse Rama con el planteamiento literario vanguardista comprometido de Cortázar (el Cortázar posterior a Rayuela, más o menos) considera sus razones políticas espurias, incoherentes y poco fiables: el "literato puro" al que, en determinada circunstancia, le da la manía política. Asimismo, indicadora del cambio de perspectiva en relación con el "compromiso" de Cortázar luego del declive de las ideologías políticas de los años 196os, resulta la lectura que hace Juan Villoro, anatemizando los textos políticos del Cortázar, denunciando sus "títulos impresentables", su cursilería política y noñería vanguardista. En Villoro, que escribe una crónica de tono autobiográfico contando su acercamiento a Cortázar - y su literatura-, es importante el proceso de autoconstrucción como escritor estético, rebelde y desideologizado, y en el que Cortázar funciona como medio para tal instalación. En este sentido, la literatura de Cortázar deviene humus particularmente aprovechable para el florecimiento de la figura del autor, con la que se salvaguardan los lugares comunes de la literatura, y su narrativa: admiración, lucha, parricidio, consagración. Explica Villoro:

Dejé de releer a Cortázar como quien lucha contra una adicción, en busca de un camino que no significara poner mis pasos en sus huellas. Conservé en la memoria las atmósferas entre lo real y lo fantástico y la liberadora voluntad de estilo. Quizá en busca de un remedio para una pasión extrema, me decepcioné con el Cortázar tardío, el de las simplificaciones políticas, la frágil invención de los cronopios (aunque ahí, en esa estética tan Walt Disney, asomaban las insuperables instrucciones para subir una escalera), la cursilería (desplegada no sólo en sus fatídicas letras de tango, sino en la solidaridad izquierdista que lo rescató del solipsismo y el aislamiento en París, pero le sugirió títulos impresentables, como Nicaragua tan violentamente dulce), la filosofía kitsch (de la tesis del "lector hembra" en Rayuela al valor trascendente de la masturbación y del coito anal en Libro de Manuel), los juegos ñoños (Los autonautas de la cosmopista, Fantomas contra los vampiros multinacionales). Necesitaba a un último Cortázar, desastroso y vencido por su propia obra, para librarme de él (Villoro 8-9).

La figura y la disciplina del autor como figura funcional de un sistema cultural y un mercado editorial, y, por tanto, cargado de trascendencia, perviven en este caso en base a una suplantación generacional en que se salvaguarda la retórica evolutiva (Villoro actual que desplaza a Cortázar pasado). Lo que dice 
Villoro, por tanto, es que Cortázar ha traicionado esa estructura funcional y trascendente (la del llamado boom narrativo latinoamericano) al incurrir en un proyecto estético-político que resulta degradado. Así pues, más allá del disenso político que puede provocar el Cortázar izquierdista, opera ese otro disenso, en apariencia más estético, en que se reclama - como en cierto sentido hace también Rama- un consumo más exclusivamente estético y hedonista de su literatura.

Sin embargo, tal como se deja ver en la lectura de Moreiras, hay algo en la propuesta estética-política de Cortázar que atenta, en cierto sentido, con la comodidad funcional e institucional de la literatura. De hecho, este fue uno de los problemas fundamentales que se planteó Cortázar al querer conjugar literatura y vida (política). Según lo propone Alazraki, Cortázar "[f]ue un inconformista enamorado de esa misma tradición contra la cual se volvió" (1). Alazraki hace un recorrido por la obra de Cortázar desde Los Reyes hasta Libro de Manuel y los relatos de Deshoras evidenciando cómo el compromiso de Cortázar con la historia política estaba implícito en su obra, y cómo sobrevinieron coyunturas históricas (la revolución cubana, fundamentalmente: su camino de Damasco), ${ }^{7}$ y autoriales (textos paradigmáticos que marcan cambios fundamentales: el conocido cuento "Reunión", por ejemplo) que consolidaron tal compromiso. Alazraki se ocupa, pues, de demostrar cómo la obra de Cortázar "lo había ido empujando hacia ese encuentro" con la historia latinoamericana (5). Esta es básicamente la tesis de Alazraki: que hay una relación interna entre estética y política, a partir del despliegue diacrónico de la obra de Cortázar. Y si bien su lectura corre el riesgo de la teleología, asimismo puede observarse cierta operatividad de lo que Ricoeur llamaría ipseidad: una construcción de la identidad que integra el acaecer y se sostiene en la capacidad de promesa (113). ${ }^{8}$ Aplicando la tesis de Ricoeur, no habría una predisposición revolucionaria como tal en Cortázar sino un contexto histórico en el que se inscriben paralelamente la experiencia individual y la promesa vanguardista de reconciliar arte y vida, reservando, por tanto, un orden performativo al deseo vanguardista de cambiar la vida.

Esta relación no es, por supuesto, tersa. De hecho, una conclusión importante que se puede derivar del acercamiento de Alazraki a Cortázar es que el mito de la modernidad (sostenido por valores heredados) engendra lo horroroso y abyecto, y que el texto literario de Cortázar por lógica (re)presenta ese estado funesto el

7 El propio Cortázar se refiere a Cuba como su camino de Damasco; al respecto véase (Gilman 3).

8 Sobre la tensión entre promesa y relación heterológica, con lo otro o el otro, ver Derrida (139140). 
que trata también de superar. En otras palabras, la obra de Cortázar revelaría una interrelación entre vanguardias y represión moderna. Propone Alazraki:

Y si en "El perseguidor" y en Rayuela se cuestionan esos valores heredados en tanto componentes de esa cultura de Occidente contra la cual se vuelven Johnny y Horacio (siempre me ha parecido revelador el que los militares argentinos se escudaran en esa tradición para perpetrar las atrocidades más repugnantes a esa tradición y que, en cambio, aquel que cuestionó los valores de esa tradición fuera quien quitara tapujos para denunciar en toda su crudeza las "atrocidades civilizadas" de nuestros "padres de la patria"), en Los premios hay un primer esfuerzo de crítica de los valores y de la historia de Argentina" (12).

Lo que queda entre paréntesis en la cita de Alazraki parece fundamental al mostrar un vínculo ideológico entre la modernidad cultural, vista como valor tradicional de lo occidental, y la dictadura o el estado de excepción (lo que se podría hacer confluir en el concepto de modernidad contrainsurgente). Desde este punto de vista, la radicalidad vanguardista de Cortázar cumpliría una labor reveladora de la intimidad entre modernidad y horror, misma operación visible también en "Apocalipsis de Solentiname".

Por supuesto, los procesos de ipseidad que se pueden advertir en la relación de Cortázar y su obra no están exentos de la gravitación de otros factores, entre ellos, asuntos tan importantes dentro del campo cultural como lo son la fama y el mercado. En una iluminadora lectura, Ricardo Piglia integra como variable válida de análisis la cuestión de la fama del Cortázar posterior a Rayuela (por tanto volviendo decisiva la presencia del mercado en su desenvolvimiento como escritor), que operaría como catalizador de una crisis literaria y política. Si bien Piglia mantiene la idea de un descenso de calidad literaria en el Cortázar posterior a Rayuela, ${ }^{9}$ sostiene, sin embargo, la idea de un solo código originario tanto de la radicalidad vanguardista de Cortázar como de su opción izquierdista. Dice Piglia: [Cortázar] trató de mantenerse fiel a su ideología de la negatividad estética, a su poética de la vanguardia y politizó su figura pública adhiriendo a la causa de la revolución. Sin duda, se pueden discutir todas las posiciones políticas de Cortázar... pero no se puede ver ahí una contradicción con sus postulados

9 En contraste, la opinión de Alazraki (16) sobre los cuentos de Deshoras (1983), última colección de cuentos de Cortázar, que "se cuentan entre sus mejores relatos". Gilman, por su parte, dice que "queda por ver si lo escrito [por Cortázar] en este último período es menos prolífico y/o menos valioso que su obra precedente" (13). 
literarios o una traición a sus fidelidades artísticas ni se pueden, tampoco, aceptar las críticas que enuncian los intelectuales moderados que cultivan el lugar común y el justo medio (85).

Ese código único de inscripción de una lógica vanguardista con doble sentido (estético y político) es el que creo se debe recuperar al hablar del Cortázar viajero en el trópico nicaragüense. Esto conlleva tentar una hermenéutica en la que los significados no sean consumidos "internamente" a la lógica literaria o del mercado literario, sino que, sin desdecirse de su expresión retórica y su localización estética, integre un exterior contextual y proyectivo con el que esa esencia literaria tendría una relación fundamental (si bien probablemente expectante u opaca).

En este sentido, el libro Nicaragua tan violentamente dulce (1984) despliega la relación entre la índole heterológica-estética (deseo de encuentro con el otro) y la utópica-política (intención de construir una nueva sociedad) en los textos del Cortázar politizado. Tomando como eje su relación con Nicaragua y su localización como viajero en el trópico, el proyecto de Cortázar se vio confrontado a la cuestión fundamental de la (nueva) soberanía política intentada por la revolución sandinista (1979-1990) con sus implicaciones, entre ellas la existencia de lenguajes institucionales y la necesidad de control sobre el territorio, que conllevó, como se verá después, la reaparición taxonómica de la barbarie, o del conflicto naturaleza-civilización.

\section{Boom y transnacionalismo}

$\mathrm{Al}$ considerar una identidad vanguardista en Cortázar, asociada al contexto del llamado "boom" literario latinoamericano, creo que se deben tomar en cuenta tres instancias interrelacionadas. En primer lugar, el "boom" como culminación de la instalación vanguardista en América Latina. En segundo lugar, las divisas de Totalidad e Innovación como características de la estética modernista/vanguardista según lo ha planteado Fredric Jameson (117), y en tercer lugar, el impulso performativo que sostiene los textos politizados de Cortázar, en particular ficciones que implican denuncias, promesas y deseos de cambio, como "Apocalipsis de Solentiname".

Neil Larsen encuentra que el "boom" merece ampliamente la designación de modernist (67), equivalente, salvando la distancia cultural, a la identificación como vanguardista. El esplendor vanguardista del boom daría sentido, en una operación genealógica típica de invención de precursores, a los narradores de la generación anterior: Borges, Asturias, Rulfo (68). En el argumento de Larsen esta 
instalación vanguardista del "boom" oculta otras tradiciones no vanguardistas, principalmente una tradición realista $(68,72)$. Como muestra Larsen, además, la identidad política del "boom" es controversial. Si por una parte indica una modificación y crecimiento del mercado del libro, por otra parte aparece de forma general asociado e identificado, por lo menos hasta el momento del caso Padilla, con la revolución cubana, aunque paradójicamente su forma de representación sea modernista/vanguardista, no realista, en el entendido que lo realista representa una postura más politizada que una representación alegórica/modernista. ${ }^{10}$ Esto aparece relacionado con la capacidad de la alegoría modernista de interrelacionar Totalidad e Innovación, o "los rasgos fundamentales o semas del alto modernismo en una especie de impulso demiúrgico en el que un deseo llamado totalidad, de un modo en cierta manera imposible, se conjunta con un deseo llamado innovación o, simplemente, lo Nuevo" (Jameson 117). Este impulso ha sido institucionalizado como "monádico", visto ya en obras constituidas que separan un contexto pero su articulación es también diacrónica, revisa tradiciones e inventa lo nuevo (Jameson 117).

Obviamente la obra de Cortázar aparece atrapada en estas lógicas de relación con la modernidad y la modernización. Encarnando tal modernidad en la alegoría narrativa, la obra de Cortázar, como se ha mostrado en el apartado anterior, da con el horror. Pero además gravita en la lógica enunciativa - por lo menos desde Rayuela - , la cuestión del mercado y la celebridad. El autor Cortázar asume las premisas del "alto modernismo" en el deseo alegórico totalizador pero también aparece marcado como figura célebre que presta su nombre a la causa revolucionaria. Cortázar resulta así conformado por varias distancias: con respecto a una forma "realista" de representación, con respecto a una pureza literaria divorciada de la lógica del mercado, e, igualmente decisivo, con respecto a la posibilidad de la promesa vanguardista de cambiar la realidad. A este punto de enunciación conflictivo se agregó un componente fundamental en el auge de las dictaduras latinoamericanas durante los años 1970s que no hace sino radicalizar la ubicación performativa del texto literario, queriendo indicar con esto un deseo de incidencia en la realidad. De hecho, no parece posible separar en Cortázar su afiliación vanguardista de la supuesta capacidad incidente del texto literario, incluso si esta se expresa en forma negativa, o lo que Jaime Villareal llama "lectofobia", cuando el peso terrible de la realidad política (el apocalipsis que irrumpe en el paraíso) lleva al "dilema ético que refuta el hedonismo de la lectoescritura"

10 El planteamiento clásico de Lukács, por ejemplo en Significación actual del realismo crítico (18-56). 
(64). Esa misma figura puede ser colocada dentro de las lógicas alegóricas que pujan desde la textualidad por una salida a un exterior político. ${ }^{11}$

La apertura hacia este exterior desde lo institucional literario, que por demás está mediado por el mercado de libro, es una tarea sinuosa que no se alcanza a través de una aproximación voluntarista sino a través de un campo complejo de problemas políticos y estéticos. ${ }^{12}$ En el caso de Cortázar, se plantea la cuestión de cómo ingresar al "compromiso" desde el esteticismo, cómo justificar lo revolucionario desde la forma, y, por último, el desplazamiento de la literatura por el activismo político. ${ }^{13}$ En este caso, me limito a ver cierta perspectiva relacionada con la lógica heterológica en Cortázar aplicada al caso de Nicaragua y cómo propende a funcionar a través de lo que llamaré foco de transnacionalización. Este implica una coyuntura (la revolución sandinista) en que un grupo intelectual o individuos célebres (Cortázar combina el rol de escritor con el de autor famoso) usa su notoriedad como arma política, de propaganda y defensa de un proyecto político. Todo esto tiene implicaciones también hacia dentro del proceso revolucionario (por ejemplo, en la recepción que le brindan los escritores de izquierda). ${ }^{14}$

En el caso de Cortázar esta articulación presenta, por supuesto, una base ética y estética soportada por las posiciones vanguardistas y la elaboración alegórica de la modernidad. En ese sentido, quizá no sea exagerado afirmar que, sobre todo, a partir de Rayuela, Cortázar entiende la relación con el otro en términos de relación de lectura y que esta relación es construida por medio de una conversación en la que resulta fundamental el nivel evocativo: la convocatoria del sujeto/lector cómplice, una prosopopeya en que la cercanía invocada implica una ausencia. ${ }^{15}$ Como se sabe, esta tensión de lectura con el otro pretende construir una comunidad erigida en torno a la complicidad estética y marcada por la anti-solemnidad (por ejemplo, Rayuela capítulo 79). Se trata, además, de

11 Siguiendo los planteamientos de Derrida, el deseo de apertura del texto se inscribe como promesa (Derrida 36). Ver su lectura de de Man, en la que señala "la necesidad de un pasaje desde la identidad ontológica y el conocimiento hacia la resolución, la acción y la promesa". La proverbiales polémicas de Cortázar con, por ejemplo, Arguedas, Collazos o Viñas, dan cuenta de este tránsito contradictorio, ver (Gilman 8-10).

13 Es el recorrido descrito por Gilman (8-10).

14 Los sandinistas apelan a la celebridad de los miembros del "boom" para lograr apoyo político para su causa. Como Gobierno también tratan de atraer intelectuales de prestigio. El otorgamiento de la Orden Rubén Darío al propio Julio Cortázar (1982) y a Carlos Fuentes (1988) puede verse como parte de estas estrategias.

15 Es un tema típico en la escritura que busca desbordar el texto por medio de compromisos. $\mathrm{Al}$ respecto, ver Derrida (38-40). 
cierta comunidad cosmopolita o des-nacionalizada, (des)arraigada en París, que tiene no obstante una especie de desajuste ético que le es consubstancial. Esta postura puede verse, ya en tensión con la cuestión del compromiso político, en la conocida Carta de Cortázar a Roberto Fernández Retamar sobre la "Situación del intelectual latinoamericano", en donde Cortázar explica:

Para mí, Roberto, y con esto terminaré, nada de eso es fácil. El lento, absorbente, infinito y egoísta comercio con la belleza y la cultura, la vida en un continente donde unas pocas horas me ponen frente a los frescos de Giotto o los Velásquez del Prado, en la curva del Rialto del Gran Canal o en esas salas londinenses donde se diría que las pinturas de Turner vuelven a inventar la luz, la tentación cotidiana de volver como en otros tiempos a una entrega total y fervorosa a los problemas estéticos e intelectuales, a la filosofía abstracta, a los altos juegos del pensamiento y de la imaginación, a la creación sin otro fin que el placer de la inteligencia y de la sensibilidad, libran en mí una interminable batalla con el sentimiento de que nada de todo eso se justifica éticamente si al mismo tiempo no se está abierto a los problemas vitales de los pueblos, si no se asume decididamente la condición de intelectual del tercer mundo en la medida en que todo intelectual, hoy día, pertenece potencial o efectivamente al tercer mundo... (Obra crítica 42).

Este impulso fetichista y eurocéntrico, que encuentra su realización únicamente a través de una localización específica de objetos y paisajes, una jerarquización canónica de elementos y la construcción de "lectores cómplices" que sintonizan con su geografía y su taxonomía, tiene ese otro lado abyecto o perturbador que de alguna manera le es correspondiente y que en la cita recién leída Cortázar llama "tercer mundo". En la narración sobre Solentiname, las pinturas primitivistas responden a ese orbe sometido que intenta una reproducción paradisíaca y una reconciliación premoderna pero que contiene de forma fantasmática, para referir de nuevo a la lectura de Moreiras (366), la abyección y lo siniestro, revelados en el momento en que ingresa a la localización cultural universal representada por la pantalla en el apartamento parisino de Cortázar. Es importante señalar cómo la apertura o desborde de la estructuración cerrada del esteticismo se encuentra tensada por la diferencia histórica de las regiones: el contraste entre lo estetizado-europeo (París) y lo siniestro premoderno (Solentiname), y entre lo institucionalizado (el museo) y lo cercano a lo "natural" (la pintura naíf). El esteticismo eurocéntrico de Cortázar se quiebra, pues, a través del viaje y la desterritorialización. El recorrido de la región marginal marca así una instancia importante para la rearticulación de lo vanguardista en clave política-estética. 
Podría decirse entonces que aunque el compromiso de Cortázar se hace desde la semiosis del "boom" o de la vanguardia, usados como teoría, su significación política se ve complicada por la localización de las enunciaciones, implicando, en primer lugar, un dilema colonial, con lo que quiero significar ese juego geográfico entre localizaciones y estéticas, entre la universalización europea y la particularización tropical de la pintura primitivista y las dictaduras; en segundo lugar, este esquema está atravesado por el mercado que en la descripción meramente estética es invisible pero que entra en la figura del propio Cortázar, en cuanto estrella literaria del "boom", cuya razón económica está ideológicamente oculta tras el discurso latinoamericano $;^{16}$ en tercer lugar, quisiera argumentar que la relación con las revoluciones, la cubana y la nicaragüense, pero en particular esta última, añaden a este esquema una relación con la razón estatal por cuanto intercepta el momento de constitución de una nueva soberanía, erigida sobre los muertos en la insurrección sandinista. El posicionamiento transnacional que despierta en Cortázar al calor de la revolución sandinista tiene, pues, esta relación triple en que se junta lo (post)colonial, el mercado y lo estatal. Consecuentemente, la primera instancia se podría localizar en la figura del viajero o "turista político", la segunda confluye en la imagen de escritor consagrado, y la tercera enuncia al intelectual revolucionario, quien piensa la cultura revolucionaria, y al decir esto me refiero a la cultura nicaragüense que se comenzó a construir en los años ochenta.

\section{Retorno del tigre}

Me gustaría tratar de advertir estas figuras superpuestas en el texto "Retorno a Solentiname" incluido en Nicaragua tan violentamente dulce. "Retorno a Solentiname" narra la vuelta de Cortázar a las islas del Lago de Nicaragua siete años después de su primera visita. En el texto, el motivo de la aceleración histórica que significó el triunfo de la revolución aparece interrelacionado con el paisaje y, en especial, el río San Juan. Aunque no está evocado directamente, el archivo literario e histórico que ha producido esta región primigenia aparece mediando el texto de Cortázar. En "Apocalipsis de Solentiname", José Coronel Urtecho, que es el eslabón fundamental de la literatura que tiene como referente el río San Juan, era uno de los personajes del cuento junto con Ernesto Cardenal. ${ }^{17}$ En "Retorno a Solentiname" ambos personajes están ausentes, aunque Cardenal es referente de la comunidad ahora desaparecida, y es la comunidad destruida la

16 Ver la conocida intervención de Rama, "El 'boom' en perspectiva".

17 Ver particularmente los ensayos y memorias de Coronel. 
que ahora se personifica: "Y allí está el archipiélago donde la isla que abrigó la comunidad de Ernesto Cardenal va a mostrarnos las huellas del vandalismo somocista... Todo está en reconstrucción... En abril volverá Cardenal a la casa..." (75). Si se toma en cuenta el carácter celebratorio de los textos de Cortázar sobre Nicaragua, se hará más evidente que en este caso la ausencia no está mediada por la evocación y el apóstrofe convocante del otro que caracteriza el texto originario - "Apocalipsis" - Los amigos presentes son invocados como figuras anónimas: para ir a Solentiname ha aceptado "la invitación de un amigo" (82), y, en otro pasaje, "almorzamos largamente con los amigos" (84), pero en todo caso los acompañantes han perdido la identidad y el juego interpelativo que les era consubstancial en "Apocalipsis de Solentiname". Se puede asociar este silencio o ausencia en la interpelación a un sentimiento de duelo en que se figuran también los muertos en la guerra de liberación. De hecho, la destrucción de la comunidad de Solentiname por el ejército de Somoza se integra a la lectura de "Apocalipsis de Solentiname", convirtiéndolo en texto profético. ${ }^{18}$ Pero a la vez, el retorno a Solentiname habla de una imposibilidad del duelo, en parte por una decisión performativa de apuntar hacia el futuro. ${ }^{19} \mathrm{El}$ aceleramiento histórico guarda un componente primitivo (ya no en este caso el de las pinturas primitivistas) que Cortázar se ve obligado a plasmar en tono de viajero, adherido al paisaje pero circunstancial, corriendo en el flujo histórico y su analogía fluvial. A esto parece remitir el segundo párrafo de la narración, que dice:

Prodigiosa aceleración de la historia, culminando en el 19 de julio del 79, abriéndose hoy en el vasto panorama de un proceso popular que comporta tantas realizaciones tangibles, tantas metas cumplidas o cumpliéndose en medio de esto que sigue siendo pobreza, trópico, tópico trópico con sus rezagos, sus rémoras, su machismo exacerbado, América Latina en su franja más tórrida, Nicaragua tan violentamente dulce como sus bruscos atardeceres cuando del rosa y del naranja se vira a un terciopelo verde y la noche cae llena de ojos de tigre, oliente y espesa (82).

En última instancia, podría pensarse que la aceleración de la historia se hace sobre o en contra de este paisaje natural que se torna amenazante. Cortázar lamenta no saber describir paisajes para lograr transmitir "eso que Europa ha perdido hace mucho: el vago temor a lo desconocido, al misterio que empieza en

18 Ver el comentario de Moreiras al respecto (360-361).

19 Para la relación entre la imposibilidad del duelo y la promesa ver Derrida (41-46). En este caso promesa y soberanía territorial confluyen. 
las orillas del río y que el doble telón verde de la selva y los manglares oculta a la mirada" (82-83). Es un territorio sin mapa, de una "soledad sonora" en que las "sombras terribles" de los conquistadores temen "la flecha envenenada", o en el caso de los modernos viajeros, las balas del "fusil del contrarrevolucionario". ${ }^{20}$ Cortázar está trabajando, pues, con lugares tópicos del libro de viaje sobre un territorio deshistorizado que la aceleración histórica moderna apenas ha tocado. Este planteamiento parece dominado por una lógica periodística que ofrece a los lectores ocasionales del turista político una visión de primera mano a cargo, además, de un autor célebre. Sin embargo, hay también un nivel alegórico en que se está tentando el límite cultural posible de la revolución y su proyecto cultural y en el que lo silvestre y salvaje ha de ser convertido en motivo liminal entre el futuro deseable (desarrollista y enculturado), y lo deforme y excluido. La figura alegórica que incorpora esta división es el jaguar domesticado que Cortázar observa en la hacienda Santa Fe:

Será un jaguar pero tan enorme que nada lo distingue del rey de las selvas bengalíes. Lo cazaron pequeño, creció en la finca y ahí está, su territorio limitado por una irrisoria cadena que podría romper sin esfuerzo, y que le da amplio espacio para tirarse al agua de la que sale con un pez en la boca, y para jugar con los que ahora lo acariciamos recelosamente ... y yo preferiría enormemente estar más allá del alcance de la cadena pero eso no se dice en esta tierra donde de alguna manera cada uno está jugando con un tigre. $\mathrm{Y}$ cuando consigo apartarme decorosamente ..., me acuerdo de un viejo cuento donde también un tigre se paseaba por una casa de campo, y me digo que acaso estoy imaginando de nuevo todo esto ... (74)

Quisiera hacer ver que hay un complejo problema de representación en el motivo del tigre. Por un lado, encarna la presencia abyecta de lo real, ofrecido de manera siniestra por la posibilidad "americana" del paisaje y lo no civilizado. Pero por el otro, representa el tipo de soberanía frágil del Estado sandinista y el frágil control (una cadena débil dominando a un tigre) con el que aspira a controlar la situación. Hay que recordar que ya en 1983 la guerra contrarrevolucionaria es un hecho, y el mismo texto de Cortázar inscribe esta tensión política. Además, esa tensión se ha trasladado a la vida cotidiana: cada nicaragüense está jugando de forma simbólica con un tigre, de manera que la contradicción civilización-naturaleza

20 Cortázar participó en una "vigilia" en la frontera norte de Nicaragua, desafiando junto a un grupo de intelectuales los ataques de la contrarrevolución. Ver "Vigilia en Bismuna" (Nicaragua tan violentamente dulce 70-72). 
ha penetrado todos los tejidos sociales. Casi al final del texto, Cortázar vuelve a la evocación de Solentiname como lugar en donde "volverá a florecer la belleza del arte popular, con sábalos y tigres pintados y esculpidos por los niños, las mujeres, los pescadores. Todo busca aquí su camino, su equilibrio difícil" (85). El deseo de equilibrio - asociado a la representación-que Cortázar declara es paradójico, puesto que en su narración de viaje el estado natural tiene todavía mucha fuerza: los "tópicos del trópico" son todavía temibles. Una última complicación de la figura del tigre es la autorreferencia literaria al cuento "Bestiario" del libro homónimo, que constituye un llamado a cierto tipo de figuración y la mediación del arte ante la presencia tan temible de lo real. Como se recordará, en el cuento - "Bestiario"- una familia rural en la Argentina convive con un tigre al que hay que constantemente que controlar por medio de horarios e informes de su localización, pero la opacidad patriarcal de la familia induce a una muerte trágica propiciada por la niña protagonista cuando el tigre mata a uno de los ocupantes. En cierto sentido, pues, la incrustación de este cuento ya remoto en la lógica de la realidad nicaragüense y la defensa del Estado revolucionario, implica la inscripción de cierto inconsciente político de lo fantástico. "Retorno a Solentiname" trata, en efecto, de reconducir la fuerza de lo siniestro hacia una figuración que reestablezca el equilibrio. Este equilibrio es, además, político, ya que Cortázar parece reconocer la frágil soberanía con que se articula el poder de la revolución. En otros textos, como por ejemplo su discurso al recibir la Orden Rubén Darío (Nicaragua tan violentamente dulce 9o-98), este deseo de equilibrio es elaborado de forma mucho más proyectiva y política, ofreciendo la versión por así decirlo "diurna" de la alegoría del tigre. En cambio, en "Retorno a Solentiname" la metáfora-oxímoron de lo "violentamente dulce" aparece como escisión entre el deseo y la realidad, articulada en torno a la división geográfica en que el territorio bárbaro está siendo incorporado a la racionalidad estatal, y presentada al lector del escritor célebre como una crónica de aventura en el trópico, cuya verdad última se lee a partir de cierto encantamiento alegórico que impregna con sus alusiones y compromisos todo el texto.

\section{Conclusiones}

"Retorno a Solentiname" puede ser leído como un suplemento de "Apocalipsis de Solentiname" en el que se reafirma y rearticula cierto orden performativo, es decir, de reconexión con un compromiso político. El texto que promete lo hace también con relación a la modernización del territorio virginal, esto es, su sujeción a una lógica soberana que sin embargo es vacilante. En ese sentido, el texto de Cortázar, no obstante la profundidad de su compromiso y probablemente debido a 
ello, sigue siendo apocalíptico. No señala el retorno al mundo paradisíaco y primitivo sino la invisible sobreimpresión de lo real en la fantasía del viajero como lucha por una reconfiguración del mundo.

Esta enunciación alegórica tiene como base una sólida postura vanguardista y heterológica que impregna la obra de Cortázar en una deriva muy coherente que, cuestionando una producción mimética, logra, recurriendo a una articulación alegórica, complejizar la cuestión performativa del texto: el deseo y el compromiso como asunto que desborda un encierro textual, y que, de todas formas, permanece operando desde esa marca de los signos. En este sentido no debe creerse la máscara retórica de un Julio Cortázar "puro" o "idiota" que ingresa al "compromiso" como por azar y decide hacer la revolución desde el texto preciosista. Así tampoco, el mito del autor satisfecho, una vez limpiado de los pecados del compromiso, da cuenta de un proyecto literario como el de Cortázar que parece todavía radical y pasional.

\section{Obras citadas}

Alazraki,Jaime. "Imaginación e historia en Julio Cortázar". Fernando Burgos, ed. Los ochenta mundos de Cortázar. Madrid: EDI-6, 1987. 1-20

Coronel Urtecho, José. Rápido tránsito: al ritmo de Norteamérica. Managua: Nueva Nicaragua, 1985.

Cortázar,Julio. Alguien que anda por ahí. Madrid: Alfaguara, 1979.

-. Nicaragua tan violentamente dulce. Barcelona: Muchnik, 1984.

-.Argentina: años de alambradas culturales. Saúl Yurkievich, ed. Barcelona: Muchnik, 1984.

-. "Carta a Roberto Fernández Retamar. (Sobre "Situación del intelectual latinoamericano")". Obra crítica. Tomo 3. Madrid: Alfaguara, 1994. 29-43.

Derrida, Jacques. Memorias para Paul de Man. Barcelona: Gedisa, 2008.

Gilman, Claudia. "Cortázar: de escritor burgués a intelectual revolucionario". Hispamérica vol X, No 124, 2013, 3-13

González, Aníbal. "Revolución y alegoría en "Reunión" de Julio Cortázar". Fernando Burgos, ed. Los ochenta mundos de Cortázar. Madrid: EDI-6, 1987. 93-109

Harlow, Barbara. Resistance Literature. London: Routledge, 1987.

Jameson, Fredric. Las semillas del tiempo. Madrid: Trotta, 2000.

Larsen, Neil. Reading North by South: on Latin American Literature, Culture, and Politics. Minneapolis: University of Minnesota Press, 1995

Lukács, Georg. Significación actual del realismo crítico. México: ERA, 1984.

Moreiras, Alberto. "Producción heterológica en Cortázar". Tercer espacio: literatura y duelo en América Latina. Santiago: Universidad Arcis, 1999·355-385. 
Moynagh, Maureen A. Political Tourism and Its Texts.

Toronto: University of Toronto Press, 2008.

Paz Soldán, Edmundo. "Roberto Bolaño: literatura y apocalipsis". Edmundo Paz

Soldán y Gustavo Faverón, eds. Bolaño salvaje. Barcelona: Candaya, 2008. 11-30.

Peris Blanes, Jaume. "El perseguidor, de Cortázar, entre la figuración

de la vanguardia y la emergencia de una nueva subjetividad".

Revista de Crítica Literaria Latinoamericana 2011, 71-92.

Piglia, Ricardo. "Sobre Cortázar". Crítica y ficción.

Buenos Aires: Siglo Veinte, 1990. 82-87.

Rama, Ángel. “El 'boom’ en perspectiva”. Más allá del boom: literatura

y mercado. Ángel Rama, ed. Buenos Aires: Folios, 1984. 51-110.

—. Diario 1974-1983. Montevideo: Ediciones Trilce, 2001.

Ramírez, Sergio. Estás en Nicaragua. Barcelona: Muchnik, 1985.

Ricoeur, Paul. Caminos del reconocimiento. Madrid: Trotta, 2005.

Spurr, David. La retórica del imperio: el discurso colonial en periodismo, escritura de viajes y administración imperial. Santiago: Universidad Alberto Hurtado, 2013.

Titler, Jonathan. "Los dos Solentinames de Julio Cortázar". Fernando Burgos

ed. Los ochenta mundos de Cortázar. Madrid: EDI-6, 1987. 85-91.

Villarreal, Jaime. "Lectofobia, desarraigo y violencia política".

Memorias en tinta: ensayos sobre la representación de la violencia

política en Argentina, Chile y Perú. Lucero de Vivanco Roca Rey,

ed. Santiago: Universidad Alberto Hurtado, 2013 (61-77).

Villoro, Juan. "Instrucciones para (no siempre) llegar a Julio

Cortázar". Los universitarios enero 2001, 7-9. 